\title{
Research on the driving cycle of Tri-wheel vehicle
}

\section{ZHENG Jin-jun ${ }^{\mathrm{a}}$, SONG Chuan-Xue ${ }^{\mathrm{b}}$, TONG Jing ${ }^{\mathrm{c}}$}

College of Automobile, Jilin University, Changchun, Jilin Province 130022, P.R. China

azhengjj@jlu.edu.cn,bsongchx@126.com,ctongjing@jlu.edu.cn

Keywords: Tri-wheel vehicle; driving cycle; research and development

\begin{abstract}
Based on fieldwork and data statistics of the tri-wheel vehicle driving conditions, the actual driving conditions of the Tri-wheel vehicle are accurately grasped. Processing and analyzing the collected data via mathematical statistics, thus the actual driving characteristics of Tri-wheel vehicles are obtained. On the basis of that, the driving cycle that is fit the actual running of the Tri-wheel vehicle is designed. Finally, the design feasibility and practical value of the driving cycle is verified through the testing and remediation of the real prototype testing.
\end{abstract}

\section{Introduction}

Automobile driving cycle is used to describe the characteristics of speed-time history of a certain type of vehicle traveling in a specific environment. Since the vehicle driving cycle reflects how the operating conditions of the vehicle (such as road conditions, driving behaviors, traffic setting, etc.) influence the performance of the vehicle. It plays a fairly important role in automotive design and development, as well as improving and enhancing the vehicle overall performance. Nowadays, there are three leading driving cycles in the world, diving cycle of United States, of the Europe and of Japan, among which United States FTP driving cycle series and European ECE driving cycle series are adopted by many countries. Some countries with advanced automotive technology employ these driving cycles, and develop new ones, combined with traffic the peculiar conditions of their countries or regions at the same time. Currently, the driving cycles applied to a variety of different conditions amount to about 70 species. These cycle operations contribute immensely to vehicle design and development ${ }^{[1]-[2]}$.

In our country, the current GB 18352.3-2005 《Limits and measurement methods for emissions from light-duty vehicles (III, IV)》 and GB/T12545.2-2001 《 the commercial vehicle fuel consumption test methods》 has formed respectively based on the ECE15 conditions and six-condition. They did not exactly reflect the actual driving conditions of the vehicles. Therefore, it cannot effectively meet the needs in the development of automotive technology in our country. In order to establish the automotive driving cycle consistent with actual usage, many scientific research institutions and enterprises have conducted studies on the driving cycles of certain specific models and geography against our common models and typical road conditions. Among them, China Automotive Technology and Research Center and China Research Academy of Environmental Sciences have conducted studies on urban automobile driving cycles, and have developed the driving cycles reflecting actual traffic situations in China's urban passenger vehicles ${ }^{[3]-[4]}$; In regard to Beijing city bus actual driving conditions, FAW Group Technical Centre together with Jilin University have developed the city bus driving cycle through deeper study ${ }^{[5]}$. FAW Group Technical Center has established the driving cycle of the heavy duty dump truck based on developing procedures and test methods ${ }^{[6]}$.

Tri-wheel vehicle is an important agricultural transport tool, which is widely used in rural areas. In China, Tri-wheel vehicle is confined by its own structure and function, thus the roads they can operate are rather specific, mostly in the fields, or roads with poor conditions within short distance. There is not any research in the light of the Tri-wheel vehicle driving cycles at home and abroad. Therefore, in this paper, theoretical study with experimental verification and design a driving cycle of Tri-wheel vehicles are combined based on their actual driving characteristics in China. Finally, with the chassis dynamometer, the feasibility analysis of driving cycle is conducted. 


\section{Research process and methods}

Development of the Tri-wheel vehicle driving cycle is preceded through the following 5 steps: experimental planning, data collection, data analysis, driving cycle synthesis and amendment, the process is listed as shown in Fig.1.

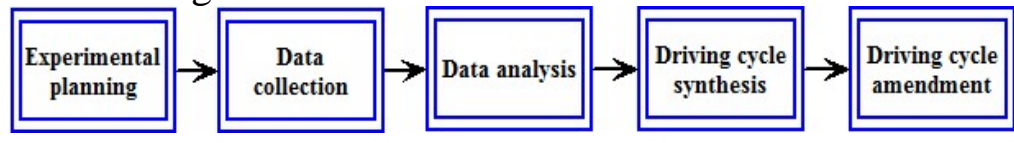

Figure 1. Steps of Tri-wheel vehicle driving cycle development

(1)Experimental planning: to determine Tri-wheel vehicle driving cycle testing lines, to select typical vehicles for the test, and to develop a test project.

(2)Data collection: the current speed and acceleration are respectively collected in operation through GPS data acquisition device installed in car. On a typical road, measurements are repeated and the real-time data are collected while operating is stored to the memory card, for further processing and analysis.

(3)Data analysis: after analysis and sorting of data, each line of Tri-wheel vehicle practical operation parameter is drawn, which includes speed, acceleration and acceleration time course curve line.

(4)Driving cycle synthesis: based on the analysis data of each line, the driving cycle in line with the Tri-wheel vehicle real driving conditions in China is synthesized via the theory of Statistics.

(5)Driving cycle amendment: a typical Tri-wheel vehicle is tested on-board via the chassis dynamometer, to amend the initial driving cycle, thus to repeatedly verify the feasibility and practicality of the initial driving cycle.

\section{Research contents}

Automobile driving cycle is mainly influenced by road types, lane numbers, traffic conditions and vehicle models. The option of road should be a comprehensive reflection of the overall traffic situations in that region. The final driving cycle should reflect all the movement of vehicles in operating status and their proportions. Table I shows the percentage of the top 10 provinces of Tri-wheel vehicle sales in January to June 2011. Typical road conditions in Henan, Hebei, Shandong and Jilin are selected as samples to conduct researches and data collection in a consecutive seven days. The annual mileage traveled in a variety of road conditions and the proportions are shown in Table II . According to the actual traffic conditions of Tri-wheel vehicles in China, we initially plan to divide a vehicle in real driving of low-speed into normal and good road conditions(paved road), mountain roads and bad roads (non-paved roads) with two different operation conditions. With the development of traffic planning in the future, as well as low-speed vehicle operating conditions improved. New developed low-speed vehicle fit for the varied traffic conditions will be developed along with it.

TABLE I. THE TOP 10 PROVINCES OF TRI-WHEEL VEHICLE SALES PERCENTAGE IN JANUARY TO JUNE 2011

\begin{tabular}{|l|c|c|c|c|c|c|}
\hline Province & Henan & Hebei & Shandong & Gansu & Shanxi & Anhui \\
\hline Ratio (\%) & 18.68 & 16.01 & 13.76 & 10.65 & 7.88 & 6.85 \\
\hline Province & Shanxi & Liaoning & Jiangsu & Neimeng & Others & - \\
\hline Ratio (\%) & 6.85 & 4.47 & 3.14 & 2.39 & 9.02 & - \\
\hline
\end{tabular}

TABLE II. THE PROPORTION OF ROAD CONDITIONS

\begin{tabular}{|c|c|c|}
\hline $\begin{array}{c}\text { Road } \\
\text { conditions }\end{array}$ & $\begin{array}{c}\text { Normal and } \\
\text { good road }\end{array}$ & $\begin{array}{c}\text { Mountain roads } \\
\text { and bad roads }\end{array}$ \\
\hline Ratio (\%) & 42.7 & 57.3 \\
\hline
\end{tabular}

\section{Data collection and statistical analysis}

The in-car GPS data acquisition device is adopted for vehicle road tests. Parameters reflecting the characteristics of vehicles of different areas are collected, road classification and the characteristic parameters used to describe vehicle's running conditions, such as average speed, average running 
time, acceleration, are respectively defined. Figures 2 and 3 are respectively for the speed-time course and the acceleration-time course of a certain line, and other lines are the similar.

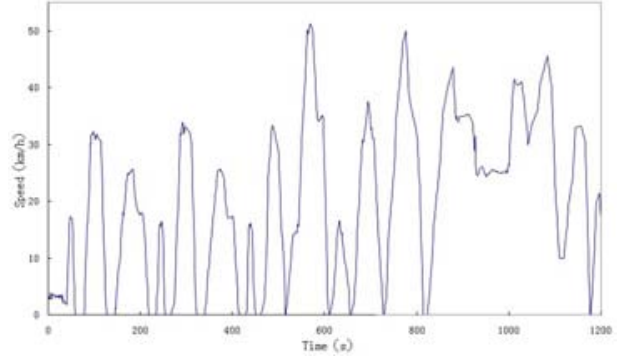

Figure 2. The speed-time course carve of Tri-wheel vehicle

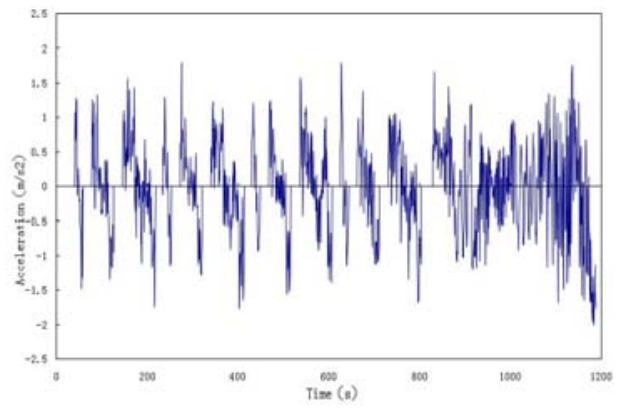

Figure 3. The acceleration -time course carve of Tri-wheel vehicle

At the same time, the main statistical characteristic values of the Tri-wheel vehicle in actual driving conditions in each line of the various provinces are calculated. These characteristic values include average speed, maximum speed, travel time, distance, idle time ratio, acceleration time ratio, uniform time ratio, deceleration time ratio, maximum acceleration, maximum deceleration in each course [7] [8]. Finally, the integrated basic parameters for the average Tri-wheel vehicle driving cycle are as shown in Table III.

TABLE III. THE BASIC PARAMETERS FOR THE DRIVING CYCLE OF TRI-WHEEL VEHICLE

\begin{tabular}{|c|ccccc|}
\hline $\begin{array}{c}\text { Road } \\
\text { conditions }\end{array}$ & $\begin{array}{c}\text { Average speed } \\
\mathbf{V}_{\mathbf{m}}(\mathbf{k m} / \mathbf{h})\end{array}$ & $\begin{array}{c}\text { Maximum } \\
\text { speed } \\
\mathbf{V}_{\max }(\mathbf{k m} / \mathbf{h})\end{array}$ & Distance) & Time (s) & $\begin{array}{c}\text { Idle time ratio } \\
\mathbf{( \% )}\end{array}$ \\
\hline Good road & 36 & 45 & 4 & 400 & 7.3 \\
\hline Bad road & 16.6 & 40 & 3.6 & 780 & 20.5 \\
\hline \hline $\begin{array}{c}\text { Road } \\
\text { conditions }\end{array}$ & $\begin{array}{c}\text { Acceleration } \\
\text { time ratio (\%) }\end{array}$ & $\begin{array}{c}\text { Deceleration } \\
\text { time ratio (\%) }\end{array}$ & $\begin{array}{c}\text { Uniform time } \\
\text { ratio (\%) }\end{array}$ & $\begin{array}{c}\text { Maximum } \\
\text { acceleration } \\
\mathbf{a}_{\text {max }}\left(\mathbf{m} / \mathbf{s}^{2}\right)\end{array}$ & $\begin{array}{c}\text { Maximum } \\
\text { deceleration } \\
\mathbf{a}_{\text {min }}\left(\mathbf{m} / \mathbf{s}^{2}\right)\end{array}$ \\
\hline Good road & 13.5 & 5.5 & 73.7 & 0.83 & -0.97 \\
\hline Bad road & 9.2 & 19.5 & 50.8 & 1.04 & -0.92 \\
\hline
\end{tabular}

Driving cycle synthesis and modification

Through the analysis of the large amounts of test data, features of the Tri-wheel vehicle in practical driving condition are concluded:(1) The speed-time course of the tested vehicles consists of several starts, accelerations, uniform speeds, decelerations, taxiing and parking parts;(2)Uniform conditions account for a larger proportion in each cycle; (3) The average speeds of each cycle are different; (4) Running time for each cycle are different (5) Average acceleration and deceleration change insignificantly in each cycle.

Based on the actual operating characteristics of these Tri-wheel vehicles and statistical theories of probability distributions above, the following synthesis methods are proposed:(1) With data measured while pulling up, acceleration, uniform and deceleration time ratio under different road conditions, the overall Tri-wheel vehicle driving cycle curves of acceleration, uniform, deceleration time are determined; (2) The acceleration time and uniform time are determined based on the range of acceleration and uniform time; (3) The acceleration of each driving segment is determined in accordance with mean and variance of acceleration; (4) Combined with acceleration, deceleration 
time and uniform time, the uniform speed is made into a ladder line. Thus a speed-time curve of the initial driving cycle is gained as shown in Fig. 5.

Due to the influence of noise in the data acquisition process, the initial driving cycle curve is not smooth enough, and the initial driving cycle part of the interval is not easy to be tracked and repeated. Thus it must be properly fixed. Table IV and V are respectively the Tri-wheel vehicle sale conditions with diesel engine configuration in January to June 2011.The top 6 kinds of Tri-wheel vehicle with $500 \mathrm{~kg}$ rating quality are selected for the initial driving cycle test on the chassis dynamometer, as shown in Fig.4 and Fig.5. According to the test results, the accelerations and decelerations are moderately revised when the speeds decrease or increase, therefore, over $80 \%$ of the Tri-wheel vehicles in the initial driving cycle test can be tracked. The curve condition can ensure the feasibility and practicality of the initial driving cycle.

TABLE IV. THE SALE CONDITION OF TRI-WHEEL VEHICLE WITH DIESEL ENGINE CONFIGURATION IN JANUARY TO JUNE 2011

\begin{tabular}{|l|l|l|l|l|l|l|l|l|l|}
\hline Engine Model & 1105 & 1115 & 1100 & 1110 & 190 & 180 & 195 & CF25 & others \\
\hline ratio(\%) & 28.47 & 21.28 & 17.91 & 6.41 & 6.21 & 4.52 & 2.29 & 1.84 & 11.07 \\
\hline
\end{tabular}

TABLE V. THE SALE CONDITION OF TRI-WHEEL VEHICLE WITH RATING QUALITY IN 1-6, 2011

\begin{tabular}{|c|l|c|}
\hline Rating quality & Sales & ratio(\%) \\
\hline $300 \mathrm{~kg}$ & 29080 & 2.75 \\
\hline $500 \mathrm{~kg}$ & 933282 & 88.30 \\
\hline $750 \mathrm{~kg}$ & 94569 & 8.95 \\
\hline
\end{tabular}

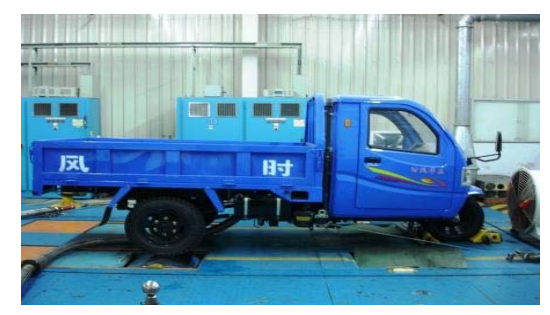

Figure 4. Tri-wheel vehicle real testing

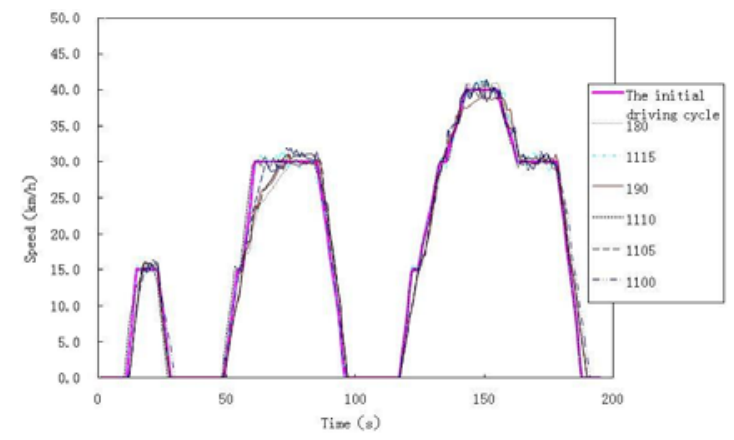

Figure 5. The initial driving cycle real testing chart of six typical Tri-wheel vehicles

Finally, we also amended the shift time and neutral gear running time of the initial driving cycle. The commonality and coordination between the Tri-wheel vehicle driving cycles and the test equipment of current enterprises and scientific research institutions is taken into account, the final driving cycle is divided into two parts: four mountainous road conditions and the bad road conditions. Then the standard driving cycle applied to the Tri-wheel vehicle is obtained, as shown in Fig.6.

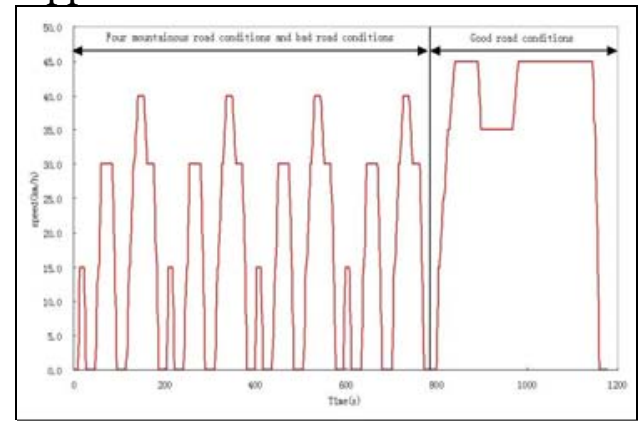

Figure 6 . The final driving cycle of Tri-wheel vehicle 
In the figure, the sum of all the Tri-wheel vehicle driving cycle working accounts for 1180s, of which four road conditions and a bad one account for 780 seconds, and good road condition accounts for 400 seconds; the driving distance is $7.6 \mathrm{~km}$; the maximum speed is $45 \mathrm{~km} / \mathrm{h}$; the average speed is $23.2 \mathrm{~km} / \mathrm{h}$; the maximum acceleration is $1.04 \mathrm{~m} / \mathrm{s} 2$; the maximum deceleration is $-0.97 \mathrm{~m} / \mathrm{s} 2$; the uniform speed time is $779 \mathrm{~s}$, which accounts for $66 \%$ of the total running time.

\section{Conclusion}

In this paper, the driving cycle of Tri-wheel vehicle reflecting actual operating conditions is firstly developed. It provides accurate, scientific and reasonable reference for the overall fuel economy tests and emission tests of the Tri-wheel vehicles, which poses great practical value; it also poses practical significance on proposing test methods with better economy and emission performance to certain extent, as well as evaluating the overall emissions level and their economic performance. What's more, the proposal of this driving cycle realizes the unification of test specification on Tri-wheel vehicles and light vehicles. It is conductive to macro-policy formulation in favor of Tri-wheel vehicle. It does great favor to manufacturers for the sake of continual employment of technology on economy, emissions performance and other related aspects.

Therefore, the utilization of laboratory equipment and personnel of related enterprises and research institutions can be raised.

\section{References}

[1] Li Mengliang,Su Maohui. Automobile urban driving cycle development [J].

[2] N. Dembski, Y. Guezennec,etal. Analysis and Experimental Refinement of Real-World Driving Cycles [J].SAE Technical Papers,2002-01-0069

[3] Li Menglian, Zhang Jianwei, Zhang Fuxing. Study on Chinese urban passenger vehicle real driving cycle [J]. Automotive Engineering,2006,6(28):554 557

[4] Liu Xiling, Ding Yan. Investigation of urban car driving cycle [J]. Environmental science,2000,13 (1):23- 28

[5] Liu Minghui, Zhao Ziliang, Jun Li, Beijing city bus driving cycle development [J]. Automotive Engineering, 2005,6(27):687 690

[6] Deng Yangqing based on the user study on the condition of heavy dump truck fuel economy [D]. Changchun: Jilin University dissertation, 2009.4

[7] Jie Lin, Markov. Process Approach to Driving cycle Development [D]. University of California, 2002

[8] Michel Andre, A. John Hickman. Driving Cycles for Emission Measurements under European Conditions [J]. SAE Technical Papers, 950926. 